Open Access

\title{
Recommendations and evidence for reporting items in pediatric clinical trial protocols and reports: two systematic reviews
}

April V. P. Clyburne-Sherin ${ }^{1}$, Pravheen Thurairajah', Mufiza Z. Kapadia ${ }^{1}$, Margaret Sampson ${ }^{2}$, Winnie W. Y. Chan ${ }^{1}$ and Martin Offringa ${ }^{1,3^{*}}$

\begin{abstract}
Background: Complete and transparent reporting of clinical trial protocols and reports ensures that these documents are useful to all stakeholders, that bias is minimized, and that the research is not wasted. However, current studies repeatedly conclude that pediatric trial protocols and reports are not appropriately reported. Guidelines like SPIRIT (Standard Protocol Items: Recommendations for Interventional Trials) and CONSORT (Consolidated Standards of Reporting Trials) may improve reporting, but do not offer guidance on issues unique to pediatric trials. This paper reports two systematic reviews conducted to build the evidence base for the development of pediatric reporting guideline extensions: 1) SPIRIT-Children (SPIRIT-C) for pediatric trial protocols, and 2) CONSORT-Children (CONSORT-C) for pediatric trial reports.

Method: MEDLINE, the Cochrane Methodology Register, and reference lists of included studies were searched. Publications of any type were eligible if they included explicit recommendations or empirical evidence for the reporting of potential items in a pediatric protocol (SPIRIT-C systematic review) or trial report (CONSORT-C systematic review). Study characteristics, recommendations and evidence for pediatric extension items were extracted. Recurrent themes in the recommendations and evidence were identified and synthesized. All steps were conducted by two reviewers.

Results: For the SPIRIT-C and CONSORT-C systematic reviews 366 and 429 publications were included, respectively. Recommendations were identified for 48 of 50 original reporting items and sub-items from SPIRIT, 15 of 20 potential SPIRIT-C reporting items, all 37 original CONSORT items and sub-items, and 16 of 22 potential CONSORT-C reporting items. The following overarching themes of evidence to support or refute the utility of reporting items were identified: transparency; reproducibility; interpretability; usefulness; internal validity; external validity; reporting bias; publication bias; accountability; scientific soundness; and research ethics.

(Continued on next page)
\end{abstract}

\footnotetext{
* Correspondence: martin.offringa@sickkids.ca

${ }^{1}$ The Hospital for Sick Children, Peter Gilgan Centre for Research and

Learning, SickKids Research Institute, Child Health Evaluative Sciences, 686

Bay Street, Toronto, ON M5G 0A4, Canada

${ }^{3}$ Senior Scientist and Program Head Child Health Evaluative Sciences, The

Hospital for Sick Children, Peter Gilgan Centre for Research and Learning, SickKids Research Institute, 686 Bay Street, Toronto, ON M5G 0A4, Canada

Full list of author information is available at the end of the article
}

\section{Biomed Central}

(c) 2015 Clyburne-Sherin et al. Open Access This article is distributed under the terms of the Creative Commons Attribution 4.0 International License (http://creativecommons.org/licenses/by/4.0/), which permits unrestricted use, distribution, and reproduction in any medium, provided you give appropriate credit to the original author(s) and the source, provide a link to the Creative Commons license, and indicate if changes were made. The Creative Commons Public Domain Dedication waiver (http://creativecommons.org/publicdomain/zero/1.0/) applies to the data made available in this article, unless otherwise stated. 
(Continued from previous page)

Conclusion: These systematic reviews are the first to systematically gather evidence and recommendations for the reporting of specific items in pediatric protocols and trials. They provide useful and translatable evidence on which to build pediatric extensions to the SPIRIT and CONSORT reporting guidelines. The resulting SPIRIT-C and CONSORT-C will provide guidance to the authors of pediatric protocols and reports, respectively, helping to alleviate concerns of inappropriate and inconsistent reporting, and reduce research waste.

Keywords: Clinical trials, Protocols, Systematic review, Reporting, SPIRIT, SPIRIT-C, CONSORT, CONSORT-C

\section{Background}

High-quality clinical trials provide the best evidence for efficacy and safety of interventions [1], and are required to improve upon our current paucity of evidence in children $[1,2]$. However, researchers have an ethical obligation to only include children in trials that are appropriately conducted and reported [1-4]. Complete and transparent reporting of trial protocols and reports ensures that these documents are useful to all stakeholders $[3,4]$, that bias is minimized [4-7], and that the research is not wasted [3, 4]. It also allows the readers of trial protocols and reports to critically assess trial methodology, ethical considerations, and internal and external validity [8].

Systematic reviews of pediatric literature have repeatedly concluded that pediatric trial reports are not appropriately reported $[3,4,6,9-17]$. Despite reporting guidelines for trial reports, reviewers identified gaps in reporting across pediatric specialties, including inadequate reporting of important items such as adverse events $[4,12,13,18]$, interventions $[12-14,19]$, outcomes $[12,20]$, sequence generation $[12,20]$, allocation concealment $[12,20]$, blinding $[11,12]$, sample size calculations [11, 12], consent and assent information [21], and many more [12, 20, 22].

Similarly, Tetzlaff et al. [23] and others [24-26] have described inappropriate reporting in trial protocols. Despite protocol-reporting guidelines, reviewers identified gaps in reporting of outcomes [24], allocation concealment [25], sample size calculations [26], and sponsor and investigator roles [27].

The SPIRIT (Standard Protocol Items: Recommendations for Interventional Trials) [28] and CONSORT (Consolidated Standards of Reporting Trials) [8] initiatives aim to harmonize and standardize reporting guidelines to tackle the problem of inappropriate reporting in trial protocols and reports, respectively. Reporting guidelines provide checklists of specific concepts, called reporting items, which need to be addressed in documents such as protocols and trial reports. SPIRIT is a protocol-reporting guideline that identifies 33 key reporting items and 17 sub-items to be addressed in all clinical trial protocols. CONSORT is a reporting guideline that identifies 25 key reporting items and 12 sub-items to be addressed in all clinical trial reports upon completion of the clinical trial. The guidelines, when followed, allow the readers of trial protocols and reports to critically assess trial methodology, ethical considerations, as well as internal and external validity. Although these guidelines may improve reporting [4], neither SPIRIT nor CONSORT offer guidance on issues unique to pediatric trials $[1-3,6,13,14,29]$.

Scientific, ethical and safety considerations for trials with children often differ from trials with adults [2]. As it is unethical to expose children to the risks of research unless it is scientifically valid, and inadequate reporting of pediatric-specific considerations may lead to biased estimates of treatment effects [6], these considerations must be accounted for in the trial protocol and report $[1,5,14,21,22,29]$. For example, growth and maturation must be considered in all aspects of pediatric trial design and interpretation [1, 3, 29] as it alters pharmacokinetics, metabolism, excretion, drug efficacy, receptors, and end-organ drug responses [2, 30-37]. Maturation and development does not happen in a linear fashion [31, 34, 38-40]. Consequently, pediatric clinical trial design requires an in-depth understanding of developmental trajectory in the eligible population during the trial period [31, 34, 38-40]. Failure to account for growth and maturation when designing a pediatric clinical trial can lead to inappropriate interventions which could result in therapeutic failure or serious adverse events in children [2, 30, 31, 33, 41, 42].

These pediatric-specific scientific, ethical and safety consideration differences have led to repeated calls for pediatric-specific reporting guidance $[1-3,6,13,14]$. Empirically developed pediatric extensions of the SPIRIT and CONSORT guidelines are needed to ensure these issues are appropriately reported in pediatric trial protocols and reports. Failure to account for these differences in trial protocols can lead to biased or inappropriate trials [4-7], or protocols that are too ambiguous to be useful to all stakeholders [3, 4]. Failure to account for these differences in trial reports can lead to biased reporting [4-7], research that is not useful to all stakeholders [3, 4], and is, therefore, considered waste of research [3].

Pediatric extensions of the SPIRIT and CONSORT guidelines will help ensure that readers can critically 
assess pediatric-specific issues relating to trial methodology, ethical considerations, trial conduct, and internal and external validity of trial results [8]. In this paper we report two systematic reviews conducted to build the evidence base for the prospective development of pediatric reporting guideline extensions: SPIRITChildren (SPIRIT-C) for pediatric trial protocols and CONSORT-Children (CONSORT-C) for pediatric trial reports. The systematic reviews to build evidence for the planned SPIRIT-C and CONSORT-C extensions will be referred to as the "SPIRIT-C systematic review" and the "CONSORT-C systematic review," respectively. Potential reporting items to be included in each extension were identified through environmental scans of existing item recommendations [1] and Delphi studies.

\section{Objectives}

The objectives of this SPIRIT-C systematic review are to: (1) identify empirical evidence to support or refute the importance of reporting original SPIRIT and candidate SPIRIT-C extension items, in terms of pediatric trial design, conduct, or interpretation, (2) identify recommendations for the reporting of specific SPIRIT and SPIRIT-C protocol items, and (3) identify any additional methodological and ethical issues that are specific to pediatric trials.

The objectives of this CONSORT-C systematic review are to: (1) identify empirical evidence to support or refute the importance of reporting original CONSORT and candidate CONSORT-C trial extension items, in terms of pediatric trial design, conduct, or interpretation, (2) identify recommendations for the reporting of specific CONSORT and CONSORT-C trial report items, and (3) identify any additional methodological and ethical issues that are specific to pediatric trials.

\section{Identification of candidate extension items}

Prior to this systematic review, candidate extension items were identified in accordance with best practices for reporting guideline extension development [43]: (1) a literature review identified the initial list of potential pediatric-specific SPIRIT-C and CONSORT-C extension reporting items; (2) a Delphi exercise contributed input from diverse stakeholders on the inclusion, exclusion, and addition of new potential SPIRIT-C and CONSORT-C extension reporting items.

The results of these systematic reviews will be brought to a consensus meeting of international pediatric trial experts and stakeholders to draft pediatric extensions of the SPIRIT and CONSORT guidelines, and will provide the evidence base of studies for the development of the SPIRIT-C and CONSORT-C Statement and Explanation and Elaboration documents.

\section{Methods}

We used the PRISMA (Preferred Reporting Items for Systematic Reviews and Meta-Analyses) reporting guideline [44] to prepare this report on our two reviews. All criteria and search terms were pre-specified, but a formal protocol was not created. An ethics approval was not required for this work.

\section{Eligibility criteria and definitions}

Publications of any type were eligible if they included explicit recommendations for reporting in a pediatric trial protocol (for the SPIRIT-C systematic review) or trial report (for the CONSORT-C systematic review), and/or if they included empirical evidence to support or refute reporting concepts in a pediatric trial protocol or trial report.

An explicit recommendation or endorsement for the reporting of an item was regarded as a recommendation. An example of a statement regarded as a recommendation for the reporting of an item follows, from Smith et al.: "We argue that parental consenting procedures should be routinely reported as a methodological feature of adolescent treatment outcome studies ..." [45].

Any information that supported or refuted the importance of a reporting item in pediatric clinical trials was defined as evidence. Our definition of evidence is consistent with the types of evidence recommended to support a reporting guideline, which includes both empirical evidence of effects or biases associated with inadequate reporting of an item and any other evidence cited to support the reporting of an item [43]. An example of a statement regarded as evidence follows, also from Smith et al.: "(Reporting of consent procedures is recommended) ... given concerns about sample bias in adolescent risk behavior research when parental consent is required, (and) ... to prospectively study the impact of consenting procedures on both the study participation rates and substance use reporting" [45].

A publication was considered pediatric if it included pediatric participants as defined by the authors of the publication. All publication years were eligible. Publication language was limited to English. Studies and conference proceedings published only as abstracts were excluded, as were duplicate or secondary publications.

\section{Information sources}

Eligible publications were identified through: a systematic search of electronic databases, reference lists of articles, a systematic review of reporting guidelines by Tetzlaff et al. [23] for the SPIRIT-C systematic review, and the EQUATOR network (Enhancing the QUality and Transparency Of health Research) database [46]. The systematic searches were conducted in MEDLINE including in-process and non-indexed citations 
(1946 - Present) and adapted for The Cochrane Methodology Register (CMR) (1995 - Present), using the Ovid interface. The last searches were run on 16 May 2014 for CONSORT-C MEDLINE, 7 July 2014 for SPIRIT-C MEDLINE and CMR, and 25 July 2014 for CONSORT-C CMR. The MEDLINE searches are presented in Additional files 1 and 2. The SPIRIT-C MEDLINE and CONSORT-C MEDLINE search were amended for the SPIRIT-C CMR and CONSORT-C CMR searches, respectively. Duplicates were removed in EndNote X6 (Thomson Reuters Corporation, New York, NY, USA).

\section{Study selection: title and abstract screening}

For each systematic review, two unblinded reviewers (ACS and PT) independently screened titles and abstracts for eligibility using the pre-defined eligibility criteria. When titles and abstracts contained insufficient information to assess whether the paper could contain recommendations or evidence as defined by the eligibility criteria, the paper was included for full-text assessment to ensure that recommendations or evidence were not missed. When the eligibility of an abstract was unclear, they were included to be re-evaluated for eligibility when reviewing full-texts during the data collection process. The result of this screening approach was that all studies addressing the pediatric population in their title or abstract were assessed in full-text as they may have contained recommendations or evidence. Abstracts that did not address the pediatric population were excluded. Disagreements on the interpretation of the eligibility criteria were resolved by consensus or by the involvement of a third reviewer (WC).

\section{Data collection process: full-text review}

Data extraction forms were developed for each systematic review, presented in Additional file 3 for SPIRIT-C and Additional file 4 for CONSORT-C, and pilot-tested on at least 10 randomly-selected included studies. Two unblinded reviewers (ACS and PT) independently extracted data from all included studies using the data extraction forms. Disagreements on the extracted data were resolved by consensus or by the involvement of a third reviewer (WC).

\section{Data items}

The following data were extracted from each included study, if found: study characteristics (first author, year, title, journal, study type, country, target population, trial design, and area of study based on the main topic of the publication itself); recommendation for reporting of an item; description of the recommendation (the intended study design, whether the recommendations were supported with evidence, and the level of that evidence); evidence for the reporting of an item; description of the evidence for the reporting of each item; recommendations for the reporting of items other than the existing SPIRIT or CONSORT items and SPIRIT-C or CONSORT-C candidate items; descriptions of trial methodology issues that are specific to trials with children or may deviate from adult trials; how these trial methodology issues may have been overcome within the studies; description of ethical issues that are specific to trials with children; and how these ethical issues may have been overcome. Due to the nature of the review, risks of bias of individual studies were not formally assessed.

\section{Thematic synthesis of results}

For each systematic review, two unblinded reviewers (ACS and PT) independently analyzed the combined extracted data from all included studies using thematic synthesis method for qualitative research [47]. The synthesis was completed in three stages: i) coding of the evidence; ii) organization of the codes into descriptive themes; and iii) development of analytical themes [47]. Thematic synthesis was outside the scope of the current study and not performed on the following data items: descriptions of trial methodology issues that are specific to trials with children or may deviate from adult trials, and how these trial methodology issues may have been overcome within the studies; description of ethical issues that are specific to trials with children, and how these ethical issues may have been overcome.

\section{Coding of the evidence}

Evidence and recommendations for the reporting of each item were identified. The evidence from the literature for the reporting of each item was coded by two reviewers inductively by the meaning and content of the evidence [47]. For example, the following evidence for the reporting of CONSORT-C Item 2a.1: "Describe the reason to perform the clinical trial in children," was extracted from Rothenberger et al.: "A solid scientific justification is an ethical requirement for studies including minors. If this justification is not satisfying, studies may be performed in adults but not in children. Ninety-one of 175 publications (52 \%) gave a scientific justification for including minors, 84 publications (48\%) did not" [48]. This example of evidence was coded as "Scientific justification." After coding the evidence, reviewers compared their codes, resolved any differences, and collaboratively created one final version of coding.

\section{Descriptive and analytic themes}

Similar codes were then grouped together by two independent reviewers to create descriptive themes in the 
meaning and content of the evidence [47]. The resulting descriptive themes were compared and differences were resolved to collaboratively create one final group of descriptive themes. One reviewer (ACS) used the descriptive themes of the evidence to infer answers to the research question: "Why recommend this pediatricspecific reporting item?" For example, evidence that was coded as "Scientific justification" was interpreted by the reviewer as answering the research question as following: "The reporting of this item ensures the inclusion of children is justified." By interpreting the descriptive themes as answers to the research question, we were able to infer analytical themes. Similar inferred answers to our research question based on the descriptive themes of the evidence were grouped together to form analytical themes. For example, the inferred answers: "The reporting of this item ensures the inclusion of children is justified" and "The reporting of this item allows readers to assess whether informed consent and assent procedures were appropriate," were grouped to form the analytical theme "Research ethics." The resulting analytic themes were reviewed by another reviewer (PT) and disagreements were collaboratively resolved to create the final group of analytic themes. Studies that contained a piece of evidence to form each analytical theme were summarized to highlight the types of analytic themes supporting potential reporting items. Due to the qualitative nature of the review, publication bias and heterogeneity were not formally assessed.

\section{Results}

A total of 2558 publications were identified through the SPIRIT-C MEDLINE and CMR database searches (Fig. 1). After screening titles and abstracts, 534 eligible full-text publications were identified. Findings from 353 relevant publications, along with 13 reporting guidelines from Tetzlaff et al. [1], were included in this review.

CONSORT-C MEDLINE and CMR database searches identified a total of 1783 publications (Fig. 2). After screening titles and abstracts, 697 eligible full-text publications were identified. Findings from 407 relevant publications, along with 22 referenced publications, were included in this review. General characteristics of the included publications for SPIRIT-C and CONSORT-C systematic reviews are shown in Tables 1 and 2 .

The largest category of the publications included in these reviews was commentary or review papers, totaling $54 \%$ of included SPIRIT-C publications and $40 \%$ of included CONSORT-C publications. The majority of included publications addressed only the pediatric population, totaling $74 \%$ of included SPIRIT-C publications and $70 \%$ of CONSORT-C included publications. Only a minority of the publications contained

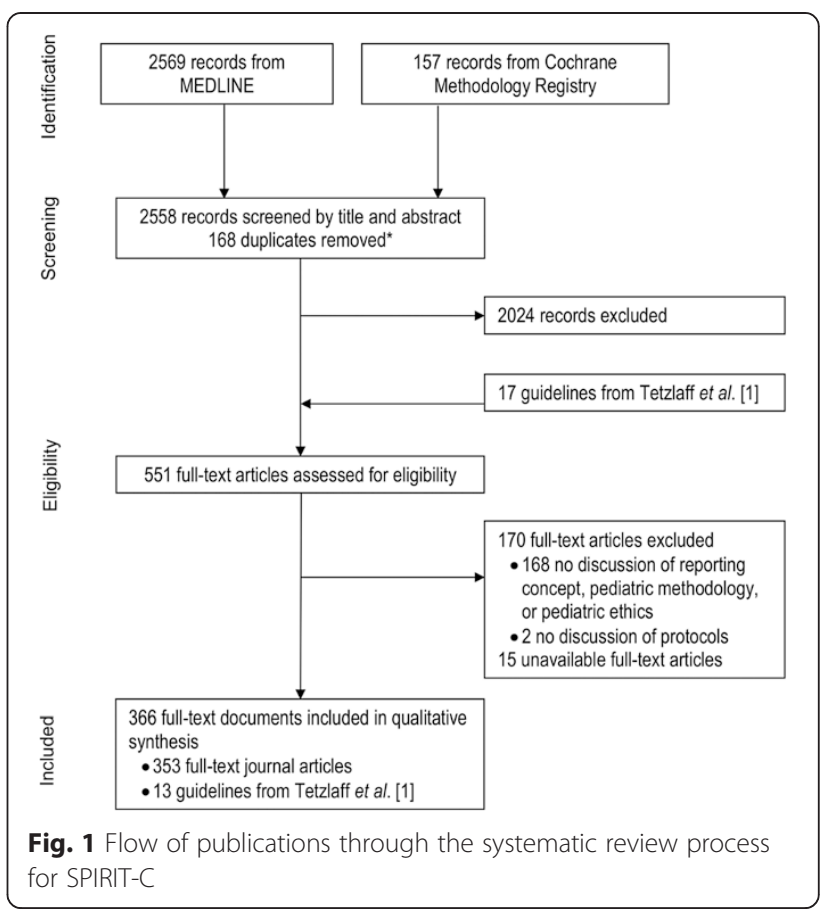

explicit recommendations for reporting, totaling $25 \%$ of SPIRIT-C included publications and $31 \%$ of CONSORT-C included publications. Of these publications that contained explicit recommendations for reporting, 54 \% of SPIRIT-C publications and $71 \%$ of CONSORT-C publications provided evidence for their recommendations.

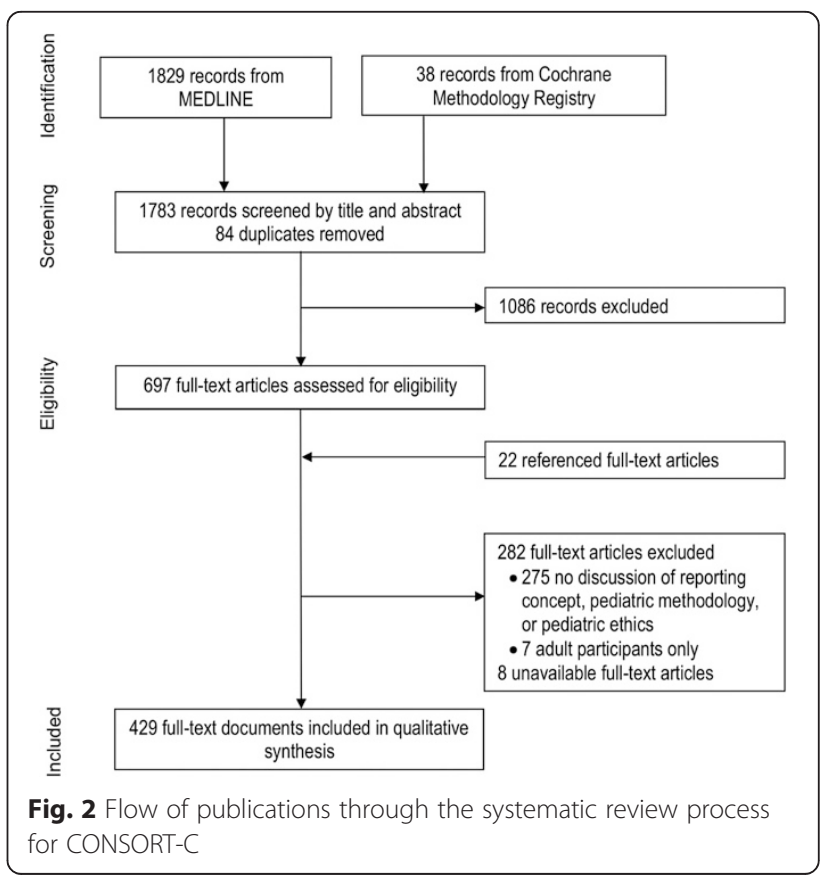


Table 1 General characteristics of the included publications for the SPIRIT-C $(n=366)$ and CONSORT-C $(n=429)$ systematic reviews

\begin{tabular}{|c|c|c|}
\hline & SPIRIT-C n (\%) & CONSORT-C n (\%) \\
\hline \multicolumn{3}{|l|}{ Type of publication } \\
\hline Clinical trial & $21(6)$ & $40(10)$ \\
\hline Systematic review & $34(9)$ & $92(21)$ \\
\hline Meta-analysis $^{a}$ & $5(1)$ & $22(5)$ \\
\hline Commentary/review ${ }^{b}$ & $197(54)$ & $173(40)$ \\
\hline Cohort/cross-sectional & $70(19)$ & $52(12)$ \\
\hline Protocol & $23(6)$ & $15(4)$ \\
\hline Other & $16(5)$ & $35(8)$ \\
\hline \multicolumn{3}{|l|}{ Target population } \\
\hline Adult only & $16(4)$ & $22(5)$ \\
\hline Pediatric only & $271(74)$ & $299(70)$ \\
\hline All & $79(22)$ & $108(25)$ \\
\hline \multicolumn{3}{|l|}{ Date of publication } \\
\hline 1971-1980 & $5(1)$ & $4(1)$ \\
\hline 1981-1990 & $18(5)$ & $15(4)$ \\
\hline $1991-2000$ & $55(15)$ & $58(13)$ \\
\hline 2001-2010 & $166(45)$ & $224(52)$ \\
\hline $2011-2014$ & $122(34)$ & $128(30)$ \\
\hline \multicolumn{3}{|c|}{ Presence of any explicit recommendation ${ }^{c}$ to report an item } \\
\hline Yes & $92(25)$ & $133(31)$ \\
\hline No & $274(75)$ & $296(69)$ \\
\hline \multicolumn{3}{|c|}{$\begin{array}{l}\text { For these explicit recommendations ( } n=92 \text { for SPIRIT, and } n=133 \text { for } \\
\text { CONSORT), evidence identified }\end{array}$} \\
\hline Yes & $54(59)$ & $95(71)$ \\
\hline No & $38(41)$ & $38(29)$ \\
\hline \multicolumn{3}{|c|}{ Source of evidence for recommendations identified } \\
\hline Literature review & $12(22)$ & $29(31)$ \\
\hline Systematic review & $5(9)$ & $28(29)$ \\
\hline Clinical trial & $2(4)$ & $3(3)$ \\
\hline Consensus & $9(17)$ & $6(6)$ \\
\hline Expert opinion & $26(48)$ & $27(29)$ \\
\hline N/A & $0(0)$ & $2(2)$ \\
\hline
\end{tabular}

Includes meta-analysis and systematic review

${ }^{\mathrm{b}}$ Includes commentaries, editorials, opinions, and non-systematic literature reviews

${ }^{c}$ As defined in Method

\section{Recommendations and evidence}

Additional files 5 and 6 summarize quantitative and qualitative information regarding the presence of recommendations and/or evidence for the reporting of items in the proposed pediatric protocol and trial report, respectively. Raw and synthesized datasets for both systematic reviews are available for download and review at (http://hdl.handle.net/10864/10880) [49]. Of the 50
Table 2 Subject foci of included publications for the SPIRIT-C $(n=366)$ and CONSORT-C $(n=429)$ systematic reviews, as identified by reviewer consensus

\begin{tabular}{llll}
\hline SPIRIT-C $n(\%)$ & \multicolumn{3}{l}{ CONSORT-C $n(\%)$} \\
\hline Disability & $8(2)$ & Alternative medicine & $7(2)$ \\
Ethics & $72(20)$ & Ethics & $38(9)$ \\
Evidence-based medicine & $17(5)$ & Evidence-based medicine & $19(3)$ \\
Infectious diseases & $6(2)$ & Immunology & $16(4)$ \\
Methodology & $176(48)$ & Infectious diseases & $11(3)$ \\
Nephrology & $3(1)$ & Mental health & $48(11)$ \\
Neurology & $9(2)$ & Methodology & $150(35)$ \\
Nutrition & $5(1)$ & Neurology & $16(4)$ \\
Obstetrics & $2(1)$ & Nutrition & $6(1)$ \\
Oncology & $8(2)$ & Obstetrics & $12(3)$ \\
Pharmacology & $20(5)$ & Oncology & $18(4)$ \\
Psychiatry & $20(5)$ & Pharmacology & $25(6)$ \\
Public health & $6(2)$ & Public health & $13(3)$ \\
Respiratory medicine & $8(2)$ & Respiratory medicine & $21(5)$ \\
Surgery & $6(2)$ & Surgery & $22(5)$ \\
& & Urology & $7(2)$ \\
\hline
\end{tabular}

Publication foci are not mutually exclusive

original reporting items and sub-items in SPIRIT, 48 were recommended for reporting by publications reviewed in systematic review; of the 20 potential extension items in SPIRIT-C, 15 were recommended. All 37 original reporting items and sub-items in CONSORT were recommended for reporting by publications reviewed, and 16 of the 22 potential extension items for CONSORT-C were recommended. No recommendation or evidence was identified that refuted the reporting of any items.

There was an average of 4.6 unique publications (standard deviation: 4.3; range: $0-17$ ) providing recommendations for the reporting of an item in SPIRIT. An average of 16.2 unique publications (standard deviation: 17.2; range: 0-63) contributed evidence for reporting a SPIRIT item. An average of 2.6 unique publications (standard deviation: 1.9; range: 0-8) provided recommendations for an item in CONSORT. On average, 27.6 publications contributed evidence for an item (standard deviation: 13.3; range: 0-82) for CONSORT. The original SPIRIT Item 26a on consent or assent was most prominently supported with 63 publications contributing evidence and the SPIRIT-C extension Item 26a.1 on the justification for the use of proxy consent and indication of who will be eligible to provide it was well-supported with 63 publications contributing evidence (Additional file 5). Within the CONSORT-C systematic review, the original CONSORT Item 2a on scientific background and explanation of rationale was most prominently 
supported with 44 publications contributing evidence and the CONSORT-C extension Item $6 a .1$ on the validity of outcomes for the age groups was well-supported by the evidence with 82 publications contributing evidence (Additional file 6).

\section{Thematic synthesis}

The empirical evidence identified for the reporting of specific items for pediatric trial protocols and trial reports was categorized into descriptive themes (see Additional file 7) and then into the following analytic themes: scientific soundness; research ethics; internal validity; accountability; external validity; transparency; reproducibility; interpretability; usefulness; reporting bias; and publication bias (see Table 3). Table 3 provides illustrative quotations from included studies supporting each analytic theme. For both SPIRIT-C and CONSORT-C, descriptive and analytical themes mirrored each other. The first five themes reflect scientific conduct of a clinical trial while the remainder deal with reporting of a clinical trial.

The systematic reviews outlined in this paper identify recommendations and evidence that could support or refute potential reporting items for pediatric protocols and trial reports. A majority of the potential reporting items had recommendations and/or evidence identified in the literature through these reviews. Both reviews further identified methodological and ethical considerations to be taken into account when conducting and reporting pediatric trials that distinctly differ from trials in adults, which we will discuss in detail below.

\section{The recommendations for the reporting of specific items in pediatric protocols and trial reports}

Our systematic reviews identified that a majority of the potential reporting items had recommendations in the literature for their reporting. These recommendations illustrate that many potential reporting items align with what these authors are already looking for in protocols and trial reports. They also suggest the need for the extension of current reporting guidelines for pediatric trials to include the pediatric-specific reporting items recommended in the articles we found in our systematic reviews. Moreover, they indicate a receptive response among the pediatric research community to the development of reporting guidelines that adopt these items.

\section{The empirical evidence for the reporting of specific items in pediatric protocols and trial reports}

Similar to the recommendations, the majority of potential reporting items had supporting evidence in the included studies. The over-arching theme was the consideration of pediatric age during the design, conduct and reporting of pediatric relevant trials. The age(s) of

Table 3 Examples of study text that were categorized in each analytic theme

\begin{tabular}{|c|c|}
\hline Analytic theme & Example of study text that was categorized within the analytic theme \\
\hline Transparency & $\begin{array}{l}\text { "It is our hope that more transparent reporting on consenting procedures, sample composition, and demographic } \\
\text { characteristics would enable future studies on the association between consenting procedures and these variables, } \\
\text { which may ultimately increase our knowledge about the impact of the unspoken rule requiring the collection of } \\
\text { parental consent." [45] }\end{array}$ \\
\hline Reproducibility & $\begin{array}{l}\text { "Other investigators should be able to replicate a vaccine trial in different settings and populations. Outcomes across } \\
\text { trials can then be compared using: for example, the same serological cutoff points at the same intervals." [14] }\end{array}$ \\
\hline Interpretability & $\begin{array}{l}\text { "Experienced practitioners and researchers also need to appreciate how setting and child characteristics affect the } \\
\text { validity and interpretation of measures." [158] }\end{array}$ \\
\hline Usefulness & $\begin{array}{l}\text { "When designing an RCT, investigators must also specify the size of the treatment effect that can be detected } \\
\text { reliably with the proposed sample size. This minimum detectable treatment difference and the actual choice of } \\
\text { the primary outcome strongly affect the clinical utility of the study results." [159] }\end{array}$ \\
\hline Internal validity & $\begin{array}{l}\text { "Hence, it is the authors' responsibility to demonstrate the measurement properties (validity, reliability, responsiveness) } \\
\text { of the outcome measures used in their studies." [160] }\end{array}$ \\
\hline External validity & $\begin{array}{l}\text { "As stated previously, investigators should justify such exclusions. Overly restrictive criteria concerning exclusion of } \\
\text { patients with concurrent diagnoses seriously limit the generalizability of study results." [161] }\end{array}$ \\
\hline Reporting bias & $\begin{array}{l}\text { "Selective reporting of clinical trials can also hamper the ability of conducting systematic reviews of the pediatric } \\
\text { literature." [89] }\end{array}$ \\
\hline Publication bias & "Registration also provides a mechanism for addressing publication bias." [162] \\
\hline Accountability & $\begin{array}{l}\text { "Why register trials? To satisfy public demand for unbiased evidence on the effectiveness of treatments, and to } \\
\text { promote the public accountability of medical research in general." [163] }\end{array}$ \\
\hline Scientific soundness & $\begin{array}{l}\text { "Environmental research with children should be scientifically justified, with sound research questions and valid } \\
\text { study protocols of sufficient statistical power ..." [164] }\end{array}$ \\
\hline Research ethics & $\begin{array}{l}\text { "In our opinion, it is very important for ethical reasons to state at least if informed consent was obtained and if the } \\
\text { study was approved by the responsible REC." [165] }\end{array}$ \\
\hline
\end{tabular}


the participating children affects all aspects of a trial, including choice of intervention and comparator, selection and measurement of relevant and valid outcomes, expected treatment effect, differences in risk/benefit profile, effects on growth and development and disease processes [21, 34, 48, 50-65]. Therefore, the detailed reporting of the age distribution of children in a trial is essential for the assessment of the appropriateness of age groups selected, the interventions, and outcomes, and the potential effects on growth and development. Within this context, three analytic themes identified in support of reporting items are summarized below, presenting some of the more prominent examples:

1. Scientific soundness. One analytic theme for reporting an item was to allow the reader to assess whether the pediatric protocol or trial report was scientifically sound. For example, the reporting of the effectiveness of an intervention in children, or lack thereof, allows the reader to critically evaluate whether the trial was scientifically justified. To justify a trial, authors must provide the reason to believe this intervention could be effective in children [66, 67], but that current information on this possible effectiveness is not conclusive [67-77]. Addressing known differences in pharmacokinetics and pharmacodynamics between children and adults allows the reader to evaluate whether the trial was justified and appropriate. The actual efficacy of interventions in the pediatric population may be impacted by changes in pharmacokinetics and pharmacodynamics due to maturation and development $[2,31,32,34,59,61,66$, 72, 78-87], insufficient data of high-quality and/or low-quantity [72, 73, 75, 76, 79], and incorrect predictions through the extrapolation of adult data [30, 32, 64, 65, 88-93]. Specifically, the reporting of the rationale and evidence for the comparator treatments used in the trial allow the reader to make appropriate scientific interpretations of the results [2, 30, 86, 87, 94-101]. Finally, our research found abundant support for the reporting of the validity of the outcomes used in every included age group to allow the reader to assess any potential for invalid outcome selection and measurement. Outcomes in all trials are recommended to be validated in the target population. Not all valid outcomes in adults are either relevant or valid in pediatric populations [31, 102-106] and not all child health outcomes are valid across various developmental stages within pediatrics [107-111]. Valid patient reported outcomes for adults may not be valid for young children [102-104, 112], proxy reports may differ from child experience [102, 112-116], symptoms in children may differ from those in adults, and what is considered healthy may differ between adults and children [21, 61, 106, 107, 117-122]. Also, due to these changes in outcomes measurement, validity of outcomes, and adverse impacts of treatment on the developmental trajectory of pediatric participants over time, the reporting of long-term monitoring of outcomes was also recommended [29, 34, 50, 123-131].

2. Research ethics. Another analytic theme for the reporting of an item was to allow the reader to assess the ethics of the trial, including whether children were protected from unnecessary research. Pediatric research should be limited to studies addressing only essential scientific questions that produce useful information [78, 118, 132]. It is not ethical to conduct research in children if comparable results can be obtained by using other methods, such as valid extrapolations from adult data or from existing data on off-label use [66, 96, 99].

Ensuring that research does not expose participants to greater than minimal risk is an ethical requirement of pediatric research and trials must take measures to reduce risks for participants. This involves reducing the pain, discomfort, distress, and invasiveness of the procedures used [31, 32, 72, 86, 88, 132-136]. Reporting blood-sampling procedures allows the reader to critically appraise whether the volume of blood drawn in pediatric studies was minimized and sampling was infrequent as possible [32, 60, 78, 86, 87, 133, 134, 137]. Additionally, inclusion of whether a Data and Safety Monitoring Board was established enables the audience to evaluate the presence of quality and safety oversight before and during the trial [22, 86, 87, 118, 138-143]. Further, detailed reporting of the trial's comparator treatments allows the ethical implications and risks associated with certain comparators to be assessed by the reader, like the risk of exposure to novel or off-label agents [134], the use of placebo or withholding of some standard care [61, 87, 101, 144, 145], and the inability of pediatric subjects to provide informed consent to use of some comparator groups $[134,146]$ make reporting of the rationale and evidence for the comparators used in the trial a necessity. Children may experience different harms from treatment than adults $[33,120,147]$, which may not be realized until years after the trial $[32,61$, $66,72,74,78,88,96,118,125,126,132,134$, $135,148-153]$. The onset of potential harms after the conclusion of the trial, possible changes in the trial's results due to the biological development of the participant, potential emergence of rare events later in the life of a child, and the increased ability of a child to better describe the harm due to their cognitive 
maturation requires that study researchers report long-term outcome monitoring procedures and how long-term safety of participants will be addressed [29, 34, 50, 123-131].

The assent of a child, when possible, is another ethical requirement for participation in pediatric trials. Therefore, the reporting of what research information was provided to children and how assent was established was recommended as age, competence, and maturity dictates the appropriateness of the aforementioned elements [32, 61, 72, 74, 78, 88, 96, $118,125,126,132,134,135,148-153]$. Reporting this information allows the reader to assess the ethics of the trial, by evaluating whether the information and assent process was appropriate, and whether the autonomy of the child was respected.

3. Internal validity. Finally, the analytic theme of internal validity was identified through our systematic reviews. Transparent reporting of certain study design, conduct, and analysis items allows the reader to assess the internal validity of the trial, including the extent to which all forms of bias were contained. As in trials outside child health, proper randomization, allocation concealment, blinding of intervention and outcome measurement, and full non- selective outcome reporting are crucial. Specifically, confounders (such as body mass index) [56, 108], assessment procedures [107-111], and test cut-off ranges may change across age and development groups. Also, the reporting of stratified randomization considerations allows the reader to assess whether the stratification variables were appropriate. The reporting of effect modification considerations allows the reader to assess the appropriateness of the considerations $[87,98]$, whether they were considered a priori $[89,154]$ and the risk of bias in the trial by evaluating whether pediatric-specific age and development-related confounding variables were accounted for $[34,70,89,117,155,156]$. The reporting of the subgroup analyses allows the reader to critically assess the validity of the trial analyses by evaluating whether analyses were decided upon before or after the trial, and whether analyses were appropriate [142, 157].

\section{Discussion}

Pediatric-specific trial protocols and trial reports need pediatric-specific guidance informed by evidence to contain bias, maximize legitimacy, and enable correct interpretation, knowledge translation, and application. Previous systematic reviews have shown inappropriate reporting of pediatric protocols [24-26] and pediatric trial reports [3, 4, 6, 9-17]. Despite repeated calls for pediatric-specific reporting guidance in the literature, there has been no previous work completed to build the evidence base to create this guidance. The recommendations and evidence we identified and summarized in this paper provide a basis for decisions to be made in a consensus meeting for the development of pediatric extensions to the current reporting guidelines. Building on the success of the SPIRIT and CONSORT guidelines, these evidence-based guidelines will help to ensure that authors who are looking to appropriately report pediatric trial protocols and trial reports have evidencebased guidance.

\section{Limitations and strengths}

While the MEDLINE and CMR databases were selected for their relevance and comprehensiveness, our electronic search was restricted to these two databases, and to English publications only. Publications were eligible based on content rather than type, and it is possible that eligible publications of types not normally indexed in electronic databases were missed. Although we did extract the level of evidence associated with the recommendations we identified, the quality of the evidence varied, and was not formally assessed due to the nature of the review. Our reviews included evidence from all publication types, most of which were narrative review publications. There is no tool for assessing the quality of evidence underpinning recommendations that would be appropriate for such reviews, the majority of the publications, which could also be applied to all other included publications [47]. As in previous qualitative systematic reviews supporting reporting guideline development, we included all eligible studies regardless of their quality [47]. Quality assessment was not necessary to meet the objectives of our systematic reviews, as they were designed to gather all relevant descriptive evidence and recommendations, and to report qualitative rather than quantitative results in accordance to best practices for reporting guideline development [43]. Due to the lack of publications that focus on the reporting of pediatric trials and protocols, and the difficulty of identifying a priori which papers would contain evidence and recommendations for reporting items, our study was structured to maximize sensitivity and capture all available evidence.

Our two systematic reviews build on the SPIRIT systematic review by Tetzlaff et al. [23], but include evidence from all publication types rather than from guidelines alone, and focus on pediatrics, where a need for guidance has been identified. This approach will help to improve the legitimacy of guidelines built upon this evidence, and to contain bias that would result from creating guidelines based on expert opinion alone. Our extensive search of multiple databases without time limits, 
along with our sensitive approach to gathering evidence, maximized the applicable evidence that could be identified. The qualitative nature of the data extraction process ensured that the context of the recommendations and evidence were contained within the reviews. We believe this allows the results to be useable and translatable to guideline developers, informing the necessary next step in creating pediatric reporting guideline extensions. Such extensions will provide guidance to the authors of pediatric protocols, helping to alleviate concerns of incomplete protocol reporting and will answer the repeated calls for pediatric-specific trial reporting to address the common repeated deficiencies in reporting of pediatric trial reports. Together, SPIRIT-C and CONSORT-C, when adopted by authors, will ensure that pediatric research is reported in a way that ensures it is useful to all stakeholders, that bias is minimized, and that the research is not wasted.

\section{Conclusions}

Our systematic reviews identified evidence and recommendations for the reporting of specific items in pediatric trial protocols and reports. These results provide useful and translatable evidence and recommendations to underpin the existing SPIRIT and CONSORT guidelines for reporting items when used in pediatric trials design and reporting. Also, these results provide foundations for pediatric-specific extensions to these reporting standards.

\section{Additional files}

Additional file 1: SPIRIT-C search strategy for Ovid MEDLINE ${ }^{\circledR}$ (including in-process \& other non-indexed citations) 1946 to July 7 2014. (PDF $225 \mathrm{~kb}$ )

Additional file 2: CONSORT-C search strategy for Ovid MEDLINE ${ }^{\oplus}$ (including in-process and other non-indexed citations) 1946 to May 16 2014. (PDF $225 \mathrm{~kb}$ )

Additional file 3: SPIRIT-C data extraction form. (PDF $530 \mathrm{~kb}$ ) Additional file 4: CONSORT-C data extraction form. (PDF $495 \mathrm{~kb}$ ) Additional file 5: Descriptive themes of evidence and recommendations identified for SPIRIT and potential SPIRIT-C extension items. (DOCX $43 \mathrm{~kb}$ )

Additional file 6: Descriptive themes of evidence and recommendations identified for CONSORT and potential CONSORT-C extension items. (DOCX $35 \mathrm{~kb}$ )

Additional file 7: Qualitative analysis: evidence from the literature organized by meaning and content, presented by descriptive themes, and sorted into analytic themes. (PDF $191 \mathrm{~kb}$ )

\section{Abbreviations}

CMR: The Cochrane Methodology Register; CONSORT: Consolidated Standards of Reporting Trials; CONSORT-C: Consolidated Standards of Reporting Trials Children; EQUATOR: Enhancing the QUality and Transparency Of health Research; SPIRIT: Standard Protocol Items: Recommendations for Interventional Trials; SPIRIT-C: Standard Protocol Items: Recommendations for Interventional Trials - Children.

\section{Competing interests}

The authors declare that they have no competing interests.

\section{Authors' contributions}

ACS, PT, and WC designed the systematic reviews with guidance from MO. MS, ACS, PT, MZK and WC developed the search strategies and the analyses plan. ACS, PT, and WC piloted the screening and extraction processes. ACS and PT selected relevant studies and extracted data, with oversight by WC. ACS and PT carried out the analysis. ACS, PT, and WC prepared the manuscript with input from MO, MZK and MS. All authors read and approved the final manuscript.

\section{Acknowledgments}

The authors thank all those who participated in the SPIRIT-C and CONSORT-C Delphi study.

\section{Funding}

These systematic reviews were funded by the Canadian Institute of Health Research Knowledge Synthesis Grant (grant number 3280016176). The funders had no role in study design, data collection and analysis, decision to publish, or preparation of the manuscript.

\section{Author details}

${ }^{1}$ The Hospital for Sick Children, Peter Gilgan Centre for Research and Learning, SickKids Research Institute, Child Health Evaluative Sciences, 686 Bay Street, Toronto, ON M5G 0A4, Canada. ${ }^{2}$ Children's Hospital of Eastern Ontario, 401 Smyth Road, Ottawa, ON K1H 8L1, Canada. ${ }^{3}$ Senior Scientist and Program Head Child Health Evaluative Sciences, The Hospital for Sick Children, Peter Gilgan Centre for Research and Learning, SickKids Research Institute, 686 Bay Street, Toronto, ON M5G 0A4, Canada.

Received: 26 February 2015 Accepted: 11 September 2015

Published online: 18 September 2015

\section{References}

1. Saint-Raymond A, Hill S, Martines J, Bahl R, Fontaine O, Bero L. CONSORT 2010. The Lancet. 2010;376(9737):229-30.

2. Hartling L, Wittmeier KD, Caldwell P, van der Lee H, Klassen TP, Craig JC, et al. StaR child health: developing evidence-based guidance for the design, conduct, and reporting of pediatric trials. Pediatrics. 2012;129 Suppl 3:S112-7.

3. Gardner F, Mayo-Wilson E, Montgomery P, Hopewell S, Macdonald G, Moher $D$, et al. The need for new guidelines to improve the reporting of trials in child and adolescent mental health. J Child Psychol Psychiatry. 2013;54(7):810-2.

4. Moher D, Sampson M, Campbell K, Beckner W, Lepage L, Gaboury I, et al. Assessing the quality of reports of randomized trials in pediatric complementary and alternative medicine. BMC Pediatr. 2002;2:2. doi:10.1186/1471-2431-2-2.

5. Dellinger RP, Vincent JL, Marshall J, Reinhart K. Important issues in the design and reporting of clinical trials in severe sepsis and acute lung injury. J Crit Care. 2008;23(4):493-9.

6. Frakking F, van der Lee J, Klassen T, Offringa M. Survey of current guidance for child health clinical trials. Standards for Research in Children: The StaR Child Health Project; 2011.

7. Dwan K, Altman DG, Arnaiz JA, Bloom J, Chan A-W, Cronin E, et al. Systematic review of the empirical evidence of study publication bias and outcome reporting bias. PLoS One. 2008;3(8):e3081.

8. Schulz KF, Altman DG, Moher D. CONSORT 2010 statement: updated guidelines for reporting parallel group randomized trials. Ann Intern Med. 2010;152(11):726-32.

9. Blakely ML, Kao LS, Tsao K, Huang EY, Tsai A, Tanaka S, et al. Adherence of randomized trials within children's surgical specialties published during 2000 to 2009 to standard reporting guidelines. J Am Coll Surg. 2013;217(3):394-9.e7.

10. Al-Namankany AA, Ashley P, Moles DR, Parekh S. Assessment of the quality of reporting of randomized clinical trials in paediatric dentistry journals. Int J Paediatr Dent. 2009;19(5):318-24.

11. Thakur A, Wang EC, Chiu TT, Chen W, Ko CY, Chang JT, et al. Methodology standards associated with quality reporting in clinical studies in pediatric surgery journals. J Pediatr Surg. 2001;36(8):1160-4. 
12. Anttila H, Malmivaara A, Kunz R, Autti-Ramo I, Makela M. Quality of reporting of randomized, controlled trials in cerebral palsy. Pediatrics. 2006;117(6):2222-30

13. Dapuzzo L, Seitz FE, Dodson WC, Stetter C, Kunselman AR, Legro RS. Incomplete and inconsistent reporting of maternal and fetal outcomes in infertility treatment trials. Fertility \& Sterility. 2011;95(8):2527-30.

14. Scott P, Ott F, Egger M, Low N. Completeness of reporting in randomized controlled trials of 3 vaccines: a review of adherence to the CONSORT checklist. Pediatr Infect Dis J. 2012;31(12):1286-94.

15. Ma B, Ke FY, Chen ZM, Qi GQ, Li HM, Liu WJ, et al. Does the reporting of randomized clinical trials published in Chinese pediatrics journals improve after the CONSORT Statement is adopted? Contemp Clin Trials. 2012;33(5):889-94.

16. Hamm MP, Hartling L, Milne A, Tjosvold L, Vandermeer B, Thomson D, et al. A descriptive analysis of a representative sample of pediatric randomized controlled trials published in 2007. BMC Pediatr. 2010;10:96.

17. Hartling L, Ospina M, Liang Y, Dryden DM, Hooton N, Krebs Seida J, et al. Risk of bias versus quality assessment of randomised controlled trials: cross sectional study. BMJ. 2009;339.

18. de Vries TW, van Roon EN. Low quality of reporting adverse drug reactions in paediatric randomised controlled trials. Arch Dis Child. 2010;95(12):1023-6.

19. Robb SL, Carpenter JS. A review of music-based intervention reporting in pediatrics. J Health Psychol. 2009;14(4):490-501.

20. Crocetti MT, Amin DD, Scherer R. Assessment of risk of bias among pediatric randomized controlled trials. Pediatrics. 2010;126(2):298-305.

21. Walleser S, Hill SR, Bero LA. Characteristics and quality of reporting of cluster randomized trials in children: reporting needs improvement. J Clin Epidemiol. 2011;64(12):1331-40.

22. Fernandes RM, van der Lee $\mathrm{JH}$, Offringa M. Data monitoring committees, interim analysis and early termination in paediatric trials. Acta Paediatr. 2011;100(10):1386-92.

23. Tetzlaff JM, Chan A-W, Kitchen J, Sampson M, Tricco AC, Moher D. Guidelines for randomized clinical trial protocol content: a systematic review. Syst Rev. 2012;1:43.

24. Chan A-W, Hróbjartsson A, Haahr MT, Gøtzsche PC, Altman DG. Empirical evidence for selective reporting of outcomes in randomized trials: comparison of protocols to published articles. JAMA. 2004;291(20):2457-65.

25. Pildal J, Chan A-W, Hróbjartsson A, Forfang E, Altman DG, Gøtzsche PC. Comparison of descriptions of allocation concealment in trial protocols and the published reports: cohort study. BMJ. 2005;330(7499):1049.

26. Chan A-W, Hróbjartsson A, Jørgensen KJ, Gøtzsche PC, Altman DG. Discrepancies in sample size calculations and data analyses reported in randomised trials: comparison of publications with protocols. BMJ. 2008;337.

27. Gøtzsche PC, Hróbjartsson A, Johansen HK, Haahr MT, Altman DG, Chan A-W. Ghost authorship in industry-initiated randomised trials. PLOS Med. 2007;4(1):e19

28. Chan A-W, Tetzlaff JM, Altman DG, Laupacis A, Gotzsche PC, Krleza-Jeric K, et al. SPIRIT 2013 statement: defining standard protocol items for clinical trials. Ann Intern Med. 2013;158(3):200-7. doi: http://dx.doi.org/10.7326/ 0003-4819-158-3-201302050-00583.

29. Sinha IP, Altman DG, Beresford MW, Boers M, Clarke M, Craig J, et al. Standard 5: selection, measurement, and reporting of outcomes in clinical trials in children. Pediatrics. 2012;129 Suppl 3:S146-52.

30. Amin SB, McDermott MP, Shamoo AE. Clinical trials of drugs used off-label in neonates: ethical issues and alternative study designs. Account Res. 2008;15(3):168-87

31. Berde CB, Walco GA, Krane EJ, Anand KJ, Aranda JV, Craig KD, et al. Pediatric analgesic clinical trial designs, measures, and extrapolation: report of an FDA scientific workshop. Pediatrics. 2012;129(2):354-64

32. Anonymous. European Union. Ethical considerations for clinical trials on medicinal products conducted with the paediatric population. Eur J Health Law. 2008;15(2):223-50

33. Ward RM, Green TP. Developmental pharmacology and toxicology: principles of study design and problems of methodology. Pharmacol Ther. 1988;36(2-3):309-34.

34. Verhamme K, Sturkenboom M. Study designs in paediatric pharmacoepidemiology. Eur J Clin Pharmacol. 2011;67 Suppl 1:67-74

35. Dumont C, Mentre F, Gaynor C, Brendel K, Gesson C, Chenel M. Optimal sampling times for a drug and its metabolite using SIMCYP() simulations as prior information. Clin Pharmacokinet. 2013;52(1):43-57. doi:http://dx.doi.org/ 10.1007/s40262-012-0022-9.
36. Laughon MM, Benjamin Jr DK, Capparelli EV, Kearns GL, Berezny K, Paul IM, et al. Innovative clinical trial design for pediatric therapeutics. Expert Rev Clin Pharmacol. 2011;4:643-52. doi:http://dx.doi.org/10.1586/ecp.11.43.

37. Morford LL, Bowman CJ, Blanset DL, Bogh IB, Chellman GJ, Halpern WG Preclinical safety evaluations supporting pediatric drug development with biopharmaceuticals: strategy, challenges, current practices. Birth Defects Res B Dev Reprod Toxicol. 2011;92(4):359-80. doi:http://dx.doi.org/ 10.1002/bdrb.20305

38. Offringa $M$, van der Lee $H$. Small sample approach, and statistical and epidemiological aspects. Handb Exp Pharmacol. 2011;205:181-202. doi:http://dx.doi.org/10.1007/978-3-642-20195-0_9.

39. Ogungbenro K, Matthews I, Looby M, Kaiser G, Graham G, Aarons L. Population pharmacokinetics and optimal design of paediatric studies for famciclovir. Br J Clin Pharmacol. 2009;68(4):546-60. doi:http://dx.doi.org/ 10.1111/j.1365-2125.2009.03479.x.

40. De Cock RF, Piana C, Krekels EH, Danhof M, Allegaert K, Knibbe CA. The role of population PK-PD modelling in paediatric clinical research. Eur J Clin Pharmacol. 2011;67 Suppl 1:5-16. doi:http://dx.doi.org/10.1007/s00228009-0782-9.

41. Price J, Hindmarsh P, Hughes S, Effthimiou J. Evaluating the effects of asthma therapy on childhood growth: principles of study design. Eur Respir J. 2002;19(6):1167-78.

42. Bradley JS. Considerations unique to pediatrics for clinical trial design in hospital-acquired pneumonia and ventilator-associated pneumonia. Clin Infect Dis. 2010;51 Suppl 1:S136-43.

43. Moher D, Schulz KF, Simera I, Altman DG. Guidance for developers of health research reporting guidelines. PLoS Med. 2010;7(2):e1000217.

44. Liberati A, Altman DG, Tetzlaff J, Mulrow C, Gøtzsche PC, loannidis JP, et al. The PRISMA statement for reporting systematic reviews and meta-analyses of studies that evaluate health care interventions: explanation and elaboration. Ann Intern Med. 2009;151(4):W-65-W-94.

45. Smith DC, Boel-Studt S, Cleeland L. Parental consent in adolescent substance abuse treatment outcome studies. J Subst Abuse Treat. 2009;37(3):298-306

46. Network E. Enhancing the quality and transparency of health research. Accessed at www. equator-network.org on 15 September 2015;9.

47. Thomas J, Harden A. Methods for the thematic synthesis of qualitative research in systematic reviews. BMC Med Res Methodol. 2008;8(1):45.

48. Rothenberger LG, Henschel AD, Schrey D, Becker A, Boos J. Methodological and ethical aspects of randomized controlled clinical trials in minors with malignant diseases.[Erratum appears in Pediatr Blood Cancer. 2012 July 15:59(1):205]. Pediatr Blood Cancer. 2011;57(4):599-605

49. Clyburne-Sherin AT, Pravheen T, Chan WY, Offringa M. Recommendations and evidence for reporting items in pediatric clinical trial protocols and reports: two systematic reviews. 2014. http://hdl.handle.net/10864/10880

50. Vray M, Girault D, Hoog-Labouret N, Porcher R, Thalabard JC. Round Table Number GXIX. Methodology for small clinical trials. Therapie. 2004;59(3):273-9. 81-6

51. Mwangoka G, Ogutu B, Msambichaka B, Mzee T, Salim N, Kafuruki S, et al. Experience and challenges from clinical trials with malaria vaccines in Africa. Malar J. 2013;12:86

52. Carleer J, Karres J. Juvenile animal studies and pediatric drug development: a European regulatory perspective. Birth Defects Res B Dev Reprod Toxicol. 2011;92(4):254-60.

53. Hiremath GS, Omer SB. A meta-analysis of studies comparing the respiratory route with the subcutaneous route of measles vaccine administration. Hum Vaccin. 2005;1(1):30-6.

54. Reed C, Madhi SA, Klugman KP, Kuwanda L, Ortiz JR, Finelli L, et al Development of the Respiratory Index of Severity in Children (RISC) score among young children with respiratory infections in South Africa. PLoS ONE [Electronic Resource]. 2012;7(1):e27793.

55. Coulibaly D, Diallo DA, Thera MA, Dicko A, Guindo AB, Kone AK, et al. Impact of preseason treatment on incidence of falciparum malaria and parasite density at a site for testing malaria vaccines in Bandiagara, Mali. Am J Trop Med Hyg. 2002;67(6):604-10.

56. Toschke AM, Kohl L, Mansmann U, von Kries R. Meta-analysis of blood pressure tracking from childhood to adulthood and implications for the design of intervention trials. Acta Paediatr. 2010;99(1):24-9.

57. Claessen JQ, Appelman CL, Touw-Otten FW, De Melker RA, Hordijk GJ. A review of clinical trials regarding treatment of acute otitis media. Clin Otolaryngol Allied Sci. 1992;17(3):251-7. 
58. Kasari C, Patterson S. Interventions addressing social impairment in autism. Curr Psychiatry Rep. 2012;14(6):713-25.

59. Glauser T, Ben-Menachem E, Bourgeois B, Cnaan A, Chadwick D, Guerreiro C, et al. ILAE treatment guidelines: evidence-based analysis of antiepileptic drug efficacy and effectiveness as initial monotherapy for epileptic seizures and syndromes. Epilepsia. 2006;47(7):1094-120.

60. Jacqz-Aigrain E. Drug policy in Europe Research and funding in neonates: current challenges, future perspectives, new opportunities. Early Hum Dev. 2011;87 Suppl 1:S27-30.

61. Spetie L, Arnold LE. Ethical issues in child psychopharmacology research and practice: emphasis on preschoolers. Psychopharmacology (Berl). 2007;191(1):15-26.

62. Gore SM. Statistical considerations in infant nutrition trials. Lipids. 1999:34(2):185-97.

63. Ramsey BW, Boat TF. Outcome measures for clinical trials in cystic fibrosis. Summary of a Cystic Fibrosis Foundation consensus conference. J Pediatr. 1994;124(2):177-92.

64. Cella M, Danhof M, Della PO. Adaptive trials in paediatric development: dealing with heterogeneity and uncertainty in pharmacokinetic differences in children. Br J Clin Pharmacol. 2012;74(2):346-53.

65. Cramer K, Wiebe N, Moyer V, Hartling L, Williams K, Swingler G, et al. Children in reviews: methodological issues in child-relevant evidence syntheses. BMC Pediatr. 2005;5:38

66. Piana C, Kliphuis E, Della PO. Lack of compliance of European Public Assessment Reports to guidelines for paediatric drug development before the introduction of paediatric investigation plans. Clin Trials. 2013;10(2):269-79.

67. Mosley C, Whittle C, Hicks C. A pilot study to assess the viability of a randomised controlled trial of methods of supplementary feeding of breast-fed pre-term babies. Midwifery. 2001;17(2):150-7.

68. Dune LS, Shiao SY. Metaanalysis of acustimulation effects on postoperative nausea and vomiting in children. Explore: The Journal of Science \& Healing. 2006;2(4):314-20.

69. Barua M, Hladunewich M, Keunen J, Pierratos A, McFarlane P, Sood M, et al. Successful pregnancies on nocturnal home hemodialysis. Clin J Am Soc Nephrol. 2008;3(2):392-6. doi:http://dx.doi.org/10.2215/CJN.04110907.

70. Kolevzon A, Mathewson KA, Hollander E. Selective serotonin reuptake inhibitors in autism: a review of efficacy and tolerability. J Clin Psychiatry. 2006;67(3):407-14

71. Ghanizadeh A, Freeman RD, Berk M. Efficacy and adverse effects of venlafaxine in children and adolescents with ADHD: a systematic review of non-controlled and controlled trials. Rev Recent Clin Trials. 2013;8(1):2-8.

72. Altavilla A. Ethical key issues and fundamental rights in paediatric research. Eur J Clin Pharmacol. 2011;67 Suppl 1:117-23.

73. Olver IN. The development of future research strategies from reviewing antiemetic trials for chemotherapy induced emesis. Rev Recent Clin Trials. 2006;1 (1):61-6. doi:http://dx.doi.org/10.2174/157488706775246094.

74. Frank E, Novick DM, Kupfer DJ. Beyond the question of placebo controls: ethical issues in psychopharmacological drug studies. Psychopharmacology (Berl). 2003;171(1):19-26.

75. Campbell M, Rapoport JL, Simpson GM. Antipsychotics in children and adolescents. J Am Acad Child Adolesc Psychiatry. 1999;38(5):537-45.

76. Bagot KS, Heishman SJ, Moolchan ET. Tobacco craving predicts lapse to smoking among adolescent smokers in cessation treatment. Nicotine Tob Res. 2007;9(6):647-52.

77. Kan P, Kestle JR. Designing randomized clinical trials in pediatric neurosurgery Childs Nervous System. 2007;23(4):385-90.

78. Cole M, Boddy AV, Kearns P, Teh KH, Price L, Parry A, et al. Potential clinical impact of taking multiple blood samples for research studies in paediatric oncology: how much do we really know? Pediatr Blood Cancer. 2006;46(7):723-7.

79. Franklin M, Foa E, March JS. The pediatric obsessive-compulsive disorder treatment study: rationale, design, and methods. J Child Adolesc Psychopharmacol. 2003;13 Suppl 1:S39-51.

80. Vitiello B. Research in child and adolescent psychopharmacology: recent accomplishments and new challenges. Psychopharmacology (Berl). 2007;191(1):5-13.

81. Knibbe CA, Krekels EH, Danhof M. Advances in paediatric pharmacokinetics. Expert Opin Drug Metab Toxicol. 2011;7(1):1-8.

82. Sharav VH. Children in clinical research: a conflict of moral values. Am J Bioethics. 2003;3(1):W-IF 2.
83. Voth M, Rosenberg M, Breuer J. Safety of gadobutrol, a new generation of contrast agents: experience from clinical trials and postmarketing surveillance. Invest Radiol. 2011;46(11):663-71.

84. Rubin RH, Shapiro ED, Andriole VT, Davis RJ, Stamm WE. Evaluation of new anti-infective drugs for the treatment of urinary tract infection. Infectious Diseases Society of America and the Food and Drug Administration. Clin Infect Dis. 1992;15 Suppl 1:S216-27.

85. Paoletti X, Geoerger B, Doz F, Baruchel A, Lokiec F, Le Tourneau C. A comparative analysis of paediatric dose-finding trials of molecularly targeted agent with adults' trials. Eur J Cancer. 2013;49(10):2392-402.

86. Sammons $\mathrm{H}$. Ethical issues of clinical trials in children: a European perspective. Arch Dis Child. 2009;94(6):474-7.

87. Ligi I, Boubred F, Grandvuillemin I, Simeoni U. Clinical research in newborn infants: difficulties and specificity. Eur J Clin Pharmacol. 2011;67 Suppl 1:29-32

88. Ackerman TF. The ethics of drug research in children. Paediatr Drugs. 2001;3(1):29-41.

89. Sampson MR, Benjamin DK, Cohen-Wolkowiez M. Evidence-based guidelines for pediatric clinical trials: focus on StaR Child Health. Expert Rev Clin Pharmacol. 2012;5(5):525-31.

90. Hausner E, Fiszman ML, Hanig J, Harlow P, Zornberg G, Sobel S. Long-term consequences of drugs on the paediatric cardiovascular system. Drug Saf. 2008;31(12):1083-96.

91. MacDonald S, Rothwell H, Moore L. Getting it right: designing adolescentcentred smoking cessation services. Addiction. 2007;102(7):1147-50.

92. Colon $\mathrm{CL}$, Ahearn WH, Clark KM, Masalsky J. The effects of verbal operant training and response interruption and redirection on appropriate and inappropriate vocalizations. J Appl Behav Anal. 2012;45(1):107-20.

93. Clemens J, Sack D, Rao M, Chakraborty J, Kay B, Ahmed F, et al. The design and analysis of cholera vaccine trials: recent lessons from Bangladesh. Int J Epidemiol. 1993;22(4):724-30.

94. Jefferson T, Price D, Demicheli V, Bianco E. European Research Program for Improved Vaccine Safety Surveillance Project. Unintended events following immunization with MMR: a systematic review. Vaccine. 2003;21(25-26):3954-60.

95. McDonagh MS, Osterweil P, Guise JM. The benefits and risks of inducing labour in patients with prior caesarean delivery: a systematic review. BJOG. 2005;112(8):1007-15.

96. O'Lonergan TA, Milgrom $\mathrm{H}$. Ethical considerations in research involving children. Curr Allergy Asthma Rep. 2005;5(6):451-8.

97. Dunlop BW, Banja J. A renewed, ethical defense of placebo-controlled trials of new treatments for major depression and anxiety disorders. J Med Ethics. 2009;35(6):384-9.

98. Hartling L, Wittmeier KD, Caldwell PH, van der Lee JH, Klassen TP, Craig JC, et al. StaR Child Health: developing evidence-based guidance for the design, conduct, and reporting of pediatric trials. Clin Pharmacol Ther. 2011;90(5):727-31. doi:http://dx.doi.org/10.1038/clpt.2011.212.

99. Knellwolf AL, Bauzon S, Alberighi OD, Lutsar I, Bacsy E, Alfarez D, et al. Framework conditions facilitating paediatric clinical research. Ital J Pediatr. 2011;37:12.

100. Brendel DH, Miller FG. A plea for pragmatism in clinical research ethics. Am J Bioethics. 2008;8(4):24-31.

101. Lindsey JC, Shah SK, Siberry GK, Jean-Philippe P, Levin MJ. Ethical tradeoffs in trial design: case study of an HPV vaccine trial in HIV-infected adolescent girls in lower income settings. Dev World Bioeth. 2013;13(2):95-104.

102. Barsevick AM, Irwin MR, Hinds $P$, Miller A, Berger A, Jacobsen $P$, et al. Recommendations for high-priority research on cancer-related fatigue in children and adults. J Natl Cancer Inst. 2013;105(19):1432-40.

103. Lande MB, Adams HR, Kupferman JC, Hooper SR, Szilagyi PG, Batisky DL. A multicenter study of neurocognition in children with hypertension: methods, challenges, and solutions. J Am Soc Hypertens. 2013;7(5):353-62.

104. Chitnis T, Tardieu M, Amato MP, Banwell B, Bar-Or A, Ghezzi A, et al. International Pediatric MS Study Group Clinical Trials Summit: meeting report. Neurology. 2013;80(12):1161-8. doi:http://dx.doi.org/10.1212/ WNL.0b013e318288694e.

105. Carlson GA, Jensen PS, Findling RL, Meyer RE, Calabrese J, DelBello MP, et al. Methodological issues and controversies in clinical trials with child and adolescent patients with bipolar disorder: report of a consensus conference. J Child Adolesc Psychopharmacol. 2003;13(1):13-27.

106. Mitchell LG, Male C. Outcome measures in interventional trials for prevention or treatment of venous thrombosis in the pediatric population. Semin Thromb Hemost. 2011;37(7):840-7. 
107. Sutherland ER, Busse WW, National Heart, Lung, and Blood Institute's AsthmaNet. Designing clinical trials to address the needs of childhood and adult asthma: the National Heart, Lung, and Blood Institute's AsthmaNet. J Allergy Clin Immunol. 2014;133(1):34-8. e1.

108. Jaspers MW, Caron H, Behrendt $H$, van den Bos $C$, Bakker $P$, Van Leeuwen F. The development of a new information model for a pediatric cance registry on late treatment sequelae in The Netherlands. Stud Health Technol Inform. 2000;77:895-9.

109. Cliff DP, Reilly JJ, Okely AD. Methodological considerations in using accelerometers to assess habitual physical activity in children aged 0-5 years. J Sci Med Sport. 2009;12(5):557-67. doi:http://dx.doi.org/10.1016/ j.jsams.2008.10.008.

110. Holgate ST, Bousquet J, Chung KF, Bisgaard H, Pauwels R, Fabbri L, et al. Summary of recommendations for the design of clinical trials and the registration of drugs used in the treatment of asthma. Respir Med. 2004;98(6):479-87.

111. Giaccone A, Jensen E, Davis P, Schmidt B. Definitions of extubation success in very premature infants: a systematic review. Arch Dis Child Fetal Neonatal Ed. 2014:99(2):F124-7.

112. Matza LS, Patrick DL, Riley AW, Alexander JJ, Rajmil L, Pleil AM, et al. Pediatric patient-reported outcome instruments for research to support medical product labeling: report of the ISPOR PRO good research practices for the assessment of children and adolescents task force. Value Health. 2013;16(4):461-79.

113. Barrett A, Clark M, Demuro C, Esser D. Proxy-reported questionnaires for young children with asthma: a structured review. Eur Respir J. 2013;42(2):513-26.

114. Tsoi WS, Zhang LA, Wang WY, Tsang KL, Lo SK. Improving quality of life of children with cerebral palsy: a systematic review of clinical trials. Child Care Health Dev. 2012;38(1):21-31.

115. Varni JW, Limbers CA, Newman DA. Using factor analysis to confirm the validity of children's self-reported health-related quality of life across different modes of administration. Clin Trials. 2009;6(2):185-95.

116. Sun GH. Bibliometric analysis of health services research in otolaryngology journals. Otolaryngol Head Neck Surg. 2012;147(5):841-7. doi:http://dx.doi.org/ 10.1177/0194599812454405

117. Sinha I, Jones L, Smyth RL, Williamson PR. A systematic review of studies that aim to determine which outcomes to measure in clinical trials in children. PLoS Medicine / Public Library of Science. 2008;5(4), e96.

118. Clausen J. Ethical brain stimulation - neuroethics of deep brain stimulation in research and clinical practice. Eur J Neurosci. 2010;32(7):1152-62.

119. Rustomjee R, McClain B, Brennan MJ, McLeod R, Chetty-Makkan CM, McShane $H$, et al. Designing an adaptive phase I//II trial to evaluate efficacy, safety and immune correlates of new TB vaccines in young adults and adolescents. Tuberculosis. 2013;93(2):136-42.

120. Anderson M, Choonara I. A systematic review of safety monitoring and drug toxicity in published randomised controlled trials of antiepileptic drugs in children over a 10-year period. Arch Dis Child. 2010;95(9):731-8.

121. Degi A, Kerti A, Kis E, Cseprekal O, Tory K, Szabo AJ, et al. Cardiovascular risk assessment in children following kidney transplantation. Pediatr Transplant. 2012;16(6):564-76.

122. Goodwin GM, Anderson I, Arango C, Bowden CL, Henry C, Mitchell PB, et al. ECNP consensus meeting. Bipolar depression. Nice, March 2007. Eur Neuropsychopharmacol. 2008;18(7):535-49.

123. Triolo RJ, Betz RR, Mulcahey MJ, Gardner ER. Application of functional neuromuscular stimulation to children with spinal cord injuries: candidate selection for upper and lower extremity research. Paraplegia. 1994;32(12):824-43.

124. Stice E, Marti CN, Spoor S, Presnell K, Shaw H. Dissonance and healthy weight eating disorder prevention programs: long-term effects from a randomized efficacy trial. J Consult Clin Psychol. 2008;76(2):329-40.

125. DiMichele DM. Ethical considerations in clinical investigation: exploring relevance in haemophilia research. Haemophilia. 2008;14 Suppl 3:122-9.

126. Hunfeld JA, Passchier J. Participation in medical research; a systematic review of the understanding and experience of children and adolescents. Patient Educ Couns. 2012:87(3):268-76.

127. Pedersen S, Szefler S. harmacological interventions. Childhood asthma. Eur Respir J Suppl. 1998;27:40s-5s.

128. Barlow J, Stewart-Brown S. Behavior problems and group-based parent education programs. J Dev Behav Pediatr. 2000;21(5):356-70.
129. Brennan L, Walkley J, Fraser SF, Greenway K, Wilks R. Motivational interviewing and cognitive behaviour therapy in the treatment of adolescent overweight and obesity: study design and methodology. Contemp Clin Trials. 2008;29(3):359-75.

130. Collins CE, Warren J, Neve M, McCoy P, Stokes BJ. Measuring effectiveness of dietetic interventions in child obesity: a systematic review of randomized trials. Arch Pediatr Adolesc Med. 2006;160(9):906-22.

131. Wirth MM, Scherer SM, Hoks RM, Abercrombie HC. The effect of cortisol on emotional responses depends on order of cortisol and placebo administration in a within-subject design. Psychoneuroendocrinology. 2011;36(7):945-54. doi:http://dx.doi.org/10.1016/j.psyneuen.2010.11.010.

132. Davidson AJ, O'Brien M. Ethics and medical research in children. Paediatr Anaesth. 2009;19(10):994-1004.

133. De Blieck EA, Augustine EF, Marshall FJ, Adams H, Cialone J, Dure L, et al. Methodology of clinical research in rare diseases: development of a research program in juvenile neuronal ceroid lipofuscinosis (JNCL) via creation of a patient registry and collaboration with patient advocates Contemp Clin Trials. 2013;35(2):48-54. doi:http://dx.doi.org/10.1016/ j.cct.2013.04.004

134. Kauffman RE. Clinical trials in children: problems and pitfalls. Paediatr Drugs. 2000;2(6):411-8

135. Shamoo AE, Moreno JD. Ethics of research involving mandatory drug testing of high school athletes in Oregon. Am J Bioethics. 2004;4(1):25-31.

136. Brown DM, Tammineni SK. Managing Sales of Beverages in Schools to Preserve Profits and Improve Children's Nutrition Intake in 15 Mississippi Schools. J Am Diet Assoc. 2009;109(12):2036-42. doi:http://dx.doi.org/ 10.1016/j.jada.2009.09.008.

137. Reif S, Schultze-Mosgau M, Sutter G. From adults to children: simulationbased choice of an appropriate sparse-sampling schedule. Paediatr Drugs. 2012;14(3):189-200.

138. Landais P, Daures JP. Clinical trials, immunosuppression and renal transplantation: new trends in design and analysis. Pediatr Nephrol. 2002;17(8):573-84

139. Modi N. Risk management in neonatal research. Seminars In Fetal \& Neonatal Medicine. 2005;10(1):99-104

140. Chalmers I, Altman DG, McHaffie H, Owens N, Cooke RW. Data sharing among data monitoring committees and responsibilities to patients and science. Trials [Electronic Resource]. 2013;14:102.

141. Holubkov R, Casper TC, Dean JM, Anand KJ, Zimmerman J, Meert KL, et al. The role of the Data and Safety Monitoring Board in a clinical trial: the CRISIS study. Pediatr Crit Care Med. 2013;14(4):374-83.

142. Pandis N, Polychronopoulou A, Eliades T. An assessment of quality characteristics of randomised control trials published in dental journals. J Dent. 2010;38(9):713-21.

143. Hinshaw SP, Hoagwood K, Jensen PS, Kratochvil C, Bickman L, Clarke G, et al. AACAP 2001 research forum: challenges and recommendations regarding recruitment and retention of participants in research investigations. J Am Acad Child Adolesc Psy. 2004;43(8):1037-45.

144. Drotar D. Commentary: randomized controlled trials of psychological interventions with pediatric populations: the time has come and the Journal of Pediatric Psychology is ready. J Pediatr Psychol. 2005;30(5):409-12

145. Schmitt HJ, Schuind A, Knuf M, Zepp F, Beutel K, von Konig CHW, et al. Acellular pertussis vaccines: the rationale for an efficacy trial in Germany. J Infect Dis. 1996;174 Suppl 3:S287-90.

146. de Melo-Martin I, Sondhi D, Crystal RG. When ethics constrains clinical research: trial design of control arms in "greater than minimal risk" pediatric trials. Hum Gene Ther. 2011;22(9):1121-7.

147. Garofalo E. Clinical development of antiepileptic drugs for children. Neurother. 2007:4(1):70-4.

148. Tait AR, Voepel-Lewis T, Malviya S. Presenting research information to children: a tale of two methods. Anesth Analg. 2007;105(2):358-64

149. John H, Worek F, Thiermann H. LC-MS-based procedures for monitoring of toxic organophosphorus compounds and verification of pesticide and nerve agent poisoning. Anal Bioanal Chem. 2008;391(1):97-116. doi:http://dx.doi.org/10.1007/s00216-008-1925-z

150. Chappuy H, Doz F, Blanche S, Gentet JC, Treluyer JM. Children's views on their involvement in clinical research. Pediatr Blood Cancer. 2008;50(5):1043-6.

151. Habers GE, Takken T. Safety and efficacy of exercise training in patients with an idiopathic inflammatory myopathy - -a systematic review. Rheumatology. 2011;50(11):2113-24. 
152. Hoppu K. Patient recruitment - European perspective. Pediatrics. 1999;104(3 Pt 2):623-6.

153. Tait AR, Voepel-Lewis T, Zikmund-Fisher BJ, Fagerlin A. Presenting research risks and benefits to parents: does format matter? Anesth Analg. 2010;111(3):718-23.

154. Contopoulos-loannidis DG, Seto I, Hamm MP, Thomson D, Hartling L, loannidis JP, et al. Empirical evaluation of age groups and age-subgroup analyses in pediatric randomized trials and pediatric meta-analyses. Pediatrics. 2012;129 Suppl 3:S161-84.

155. Jonas WB, Anderson RL, Crawford CC, Lyons JS. A systematic review of the quality of homeopathic clinical trials. BMC Complement Altern Med. 2001;1:12.

156. Reynolds S, Wilson C, Austin J, Hooper L. Effects of psychotherapy for anxiety in children and adolescents: a meta-analytic review. Clin Psychol Rev. 2012;32(4):251-62.

157. Jaykaran G, Kantharia ND, Preeti Y, Bharddwaj P, Goyal J. Reporting statistics in clinical trials published in Indian journals: a survey. Afr Health Sci. 2010;10(2):204-7.

158. Drotar D. Shared dilemmas of research and practice in developmental and behavioral pediatrics: introduction to the special issue on methodology. J Dev Behav Pediatr. 1991;12(6):347-9.

159. Zhang B, Schmidt B. Do we measure the right end points? A systematic review of primary outcomes in recent neonatal randomized clinical trials. J Pediatr. 2001;138(1):76-80.

160. Kristman VL, Borg J, Godbolt AK, Salmi LR, Cancelliere C, Carroll L, et al. Methodological issues and research recommendations for prognosis after mild traumatic brain injury: results of the International Collaboration on Mild Traumatic Brain Injury Prognosis. Arch Phys Med Rehabil. 2014;95 Suppl 3:S265-77.

161. Cotton DJ, Powderly WG, Feinberg J, Abrams DI, Chaisson RE, Wheat LJ, et al. Guidelines for the design and conduct of AIDS clinical trials. AIDS Clinical Trials Group. Clin Infect Dis. 1993;16:814-6.

162. Kleinman RE, Brown RT, Cutter GR, Dupaul GJ, Clydesdale FM. A research model for investigating the effects of artificial food colorings on children with ADHD. Pediatrics. 2011;127(6):e1575-84. doi:http://dx.doi.org/10.1542/ peds.2009-2206.

163. Mann H. ASSERT: A Standard for the Scientific and Ethical Review of Trials. 2007. http://www.assert-statement.org/. 2014.

164. Merlo DF, Knudsen LE, Matusiewicz K, Niebroj L, Vahakangas KH. Ethics in studies on children and environmental health. J Med Ethics. 2007;33(7):408-13.

165. Henschel $A D$, Rothenberger $L G$, Boos J. Randomized clinical trials in children - ethical and methodological issues. Curr Pharm Des. 2010;16(22):2407-15.

\section{Submit your next manuscript to BioMed Central and take full advantage of:}

- Convenient online submission

- Thorough peer review

- No space constraints or color figure charges

- Immediate publication on acceptance

- Inclusion in PubMed, CAS, Scopus and Google Scholar

- Research which is freely available for redistribution 